\title{
Oat Products Modulate the Gut Microbiota and Produce Anti-Obesity Effects in
}

\section{Obese Rats}

Ji-lin Dong ${ }^{\mathrm{a}, \mathrm{b}}$, Ying-ying $\mathbf{Z h u}^{\mathrm{c}, \mathrm{d}}$, Yu-ling Ma ${ }^{\mathrm{a}}$, Qi-sen Xiang ${ }^{\mathrm{a}}$, Rui-ling Shen ${ }^{\mathrm{a}, \mathrm{b} *}$, Yan-qi

\section{$\mathbf{L i u}^{\mathrm{a}}$}

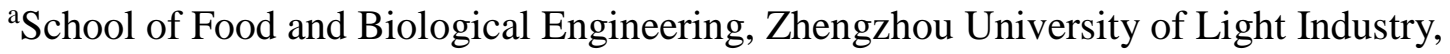

No. 166 Kexue Road, Zhengzhou 450002, Henan, China

${ }^{\mathrm{b}}$ Collaborative innovation center of food production and safety, Zhengzhou University of

Light Industry, No. 166 Kexue Road, Zhengzhou 450002, Henan, China

${ }^{c}$ Animal Science Unit, Gembloux Agro-Bio Tech, University of Liège, Passage des

Déportés 2, 5030 Gembloux, Belgium

${ }^{\mathrm{d}}$ Institute of Crop Science, Chinese Academy of Agricultural Sciences, No.80 South Xueyuan

Road, Haidian District, Beijing 100081, China

* To whom correspondence should be addressed

Phone: (86) 13526645815. Fax: (86) 0371-86609631.

E-mail: shenr11967@163.com 


\section{Abbreviations Used}

HFD, high fat diet; NC, normal controls; MC, model controls; OM, oat meal; OF, oat flour;

OB, high fiber oat bran; TC, total cholesterol; TG, triglyceride; HDL-C, high-density lipoprotein cholesterol; LDL-C, low-density lipoprotein cholesterol; PYY, peptide YY; LPS, lipopolysaccharide; LI, Lee's index; SCFA, short chain fatty acid; ET, endotoxin, IL6, interleukin-6; TNF- $\alpha$, tumor cell necrosis factor- $\alpha$; OTUs, operational taxonomy units; PCA, Principal component analysis. 


\begin{abstract}
Three oat products were supplemented into high fat diets and fed to obese rats for 8 weeks. Each oat product decreased body weight, epididymal fat accumulation, and serum inflammatory factor levels and significantly regulated serum lipid levels. Oat bran significantly reduced mean adipocyte size and TNF- $\alpha$ mRNA expression levels. Principal components analysis showed that the oat products shifted the overall structure of gut microbiota in DIO rats. The relative abundances of Bacteoidetes and Firmicutes and the Bacteroidetes/Firmicutes ratio were altered towards that of normal rats. Spearman's correlation analysis showed that changes in the overall microbiota composition were significantly correlated with total cholesterol, triacylglycerol, endotoxin, and tumour cell necrosis factor- $\alpha$ levels in serum, and mRNA expression levels. Oat products significantly increased the total short-chain fatty acids (SCFA) concentration in colonic digesta. These results suggest that oat products attenuate obesity and related metabolic disorders while modifying the gut microbiota composition in high fat diet-induced obese rats.
\end{abstract}

\title{
Keywords:
}

Oat products; Anti-obesity; TNF- $\alpha$; Gut microflora; SCFA; 


\section{Introduction}

Obesity is a major risk factor for several chronic metabolic disorders, such as dyslipidaemia, hypertension and type II diabetes (Brown, Higgins, \& Donato, 2000; Cani, Bibiloni, \& Knauf 2008). Increasing evidence suggests that dysbiosis of the gut microbiota plays a key role in the development of obesity. Previous studies reported that energy harvesting was positively associated with the number of Firmicutes in the intestine and negatively associated with the number of Bacteroidetes (Turnbaugh, Ley, \& Mahowald, 2006). In addition, a reduction of beneficial bacteria and an increase in proinflammatory/pathogenic bacteria are consistently associated with the development of systemic inflammation (Veiga, Gallini, \& Beal, 2010) and metabolic comorbidities (Zhang, Zhang, \& Wang, 2010). Previous studies showed that the composition and metabolism of gut microbiota were strongly influenced by eating habits (Scott, Duncan, \& Flint, 2008). In summary, high fat diets (HFD) induce gut microbiota dysbiosis and should be targeted as an effective approach to obesity and related chronic metabolic disorder therapy (Wang, Tang, \& Zhang, 2015).

Oat products have attracted attention for their considerable health benefits, such as weight-loss, reduction in postprandial glycemia and reduction in serum low-density lipoprotein cholesterol (LDL-C) (Shen, Cai, \& Dong, 2011; Maki, Beiseigel, \& Jonnalagadda, 2010; Guevara-Cruz, Tovar, \& Aguilar-Salinas. 2012). These physiological benefits are generally attributed to $\beta$-glucan, which is a non-starch polysaccharide 
composed of $(1 \rightarrow 3)$ and $(1 \rightarrow 4)$ linked $\beta$-D-glucopyranosyl units in varying proportions. $\beta$-Glucan is indigestible by human enzymes in the small intestine and is a prebiotic to promote bacteria growth (Shen, Dang, \& Dong, 2012). Previous reports identified that oat $\beta$-glucan increase populations of beneficial bacteria (for example, Lactobacillus and Bifidobacterium) and decreases populations of pathogenic bacteria (for example, Enterobacteriaceae) both in vivo (Shen et al., 2012) and in vitro (Simon, Peter, \& Glenn, 2008). In our daily life, our diet consists of oat products, rather than purified $\beta$-glucan. Despite these advances, the effects of oat products processed by different methods on the overall structure of gut microbiota and the relationship between these modulating effects and improvements in obesity-related metabolic disorders are poorly understood.

Most published studies on prebiotics in subjects with metabolic disorders used culturebased or targeted molecular analyses (Wang et al., 2015; Everard, Belzer, \& Geurts, 2013). Variations in microbiota composition were generally evaluated by changes in certain bacteria (Snart, Bibiloni, \& Grayson, 2006). There is limit studies on the complete profile of oat product-induced alterations in gut microbiota, because bacteria that cannot be cultured and those that share low homology with the specific probes/primers utilized remain unidentified (Wang et al., 2015). Recent developments in metagenomic sequencing represent a powerful alternative to rRNA sequencing for analyzing complex microbial communities (Riesenfeld, Schloss, \& Handelsman, 2004).

In this study, we compared the effects of oat meal (OM), oat flour (OF) and high fiber 
oat bran $(\mathrm{OB})$ on host lipid metabolism and gut microbial community structure in dietinduced obese (DIO) rats. Body weight, epididymal fat accumulation, serum lipid levels, serum inflammatory factors, tumour necrosis factor $\alpha(\mathrm{TNF}-\alpha)$ mRNA expression levels in liver and adipose tissue and colonic short-chain fatty acid (SCFA) concentrations were tested during this experiment. Histomorphological changes in adipose tissue were also observed. Furthermore, gut microbiota composition was characterized using Illumina HiSeq sequencing technology.

2 Materials and Methods

\subsection{Chemicals}

The total starch assay kit, total dietary fiber assay kit, mixed-linkage beta-glucan assay kit and resistant starch assay kit were purchased from Megazyme International Ireland Ltd. (Bray, Ireland). Commercial biochemical assay kits for triacylglycerol (TG), total cholesterol (TC), and high-density lipoprotein cholesterol (HDL-C) were purchased from BioSino Bio-technology and Science Inc. (Beijing, China). Commercial ELISA assay kits for endotoxin (ET) and tumor cell necrosis factor- $\alpha$ (TNF- $\alpha$ ) were purchased from Nanjing Jiancheng Bioengineering Institute (Nanjing, China). The E.N.Z.A. ${ }^{\circledR}$ Stool DNA isolation kit was purchased from Omega Bio-Tek Inc. (Doraville, CA, USA). Acetic acid, propionic acid, iso-butyric acid, butyric and crotonic acid standards were purchased from Sigma Inc. (St. Louis, MO, USA). Formalin, hematoxylin, and other chemicals were analytical reagent grade. 


\subsection{Materials}

OM, OF and OB were commercial products purchase from Jinlvhe Biotechnology Co., Ltd (Shanxi, China). The following nutritive components were analyzed: total dietary fiber (AOAC) method 985.29, total $\beta$-glucan content (AOAC) method 995.16, crude protein (Kjeldahl Method), crude fat (Soxhlet abstracting method), crude ash (Combustion method), total starch (AOAC) method 991.43, moisture content (Constant weight method) and resistant starch content (AOAC) method 2002.02 from the three oat products. The physicochemical characteristics, including water-retaining capacity and swelling capacity, were also determined using the methods previously described by Wang, Li, and Jiao, 2009. The apparent viscosity was measured with an NDJ-1 rotating viscometer (Hengping scientific, Shanghai, China) at specific conditions $\left(25^{\circ} \mathrm{C}, 5 \% \mathrm{M} / \mathrm{M}, 200 \mathrm{rpm}\right)(\mathrm{Xu}, \mathrm{Zhou}$, \& Wang, 2012). $\beta$-Glucan samples were prepared in a two-step method with ethanolenzymatic and water from the three oat products according to the method by Shen et al. (2012). Purification of $\beta$-glucans was performed with ion-exchange chromatography on DEAE-Sepharose CL-6B and gel chromatography on Sepharose CL-4B. The average molecular weights $\left(\mathrm{M}_{\mathrm{w}}\right)$ of the three $\beta$-glucans samples were measured using a high performance size elusion chromatography coupled with multi angle laser light scattering and refractive index (HPSEC-MALLS-RID) system. Samples were filtered on a $0.45-\mu \mathrm{m}$ membrane before injection $(100 \mu \mathrm{L})$ and eluted with $0.1 \mathrm{M} \mathrm{NaCl}(0.5 \mathrm{~mL} / \mathrm{min})$. The column temperature was kept at $40{ }^{\circ} \mathrm{C}$ (Liu, Xu, Zhang, 2012). 


\subsection{Animals and Experimental Diets}

After 7 days acclimatization, 80 male Sprague-Dawley rats (4 weeks of age, weighing $135 \pm 10 \mathrm{~g}$, obtained from the Laboratory Animal Centre of Henan Province, Zhengzhou, China, SCXK: 2010-0002) were randomly divided into two groups. The normal control (NC) group (containing 10 rats) was fed normal chow, and the other group (containing 70 rats) was first fed a high-fat diet to establish a diet-induced obesity model (DIO, the average body weights were more than $120 \%$ compared with normal rats). After 6 weeks of this modeling, 40 DIO rats were randomly subdivided into four groups (10 rats per group). One group was maintained on the HFD as model controls, and the other three groups were fed HFD supplemented with oat products (OM, OF and OB) with the same amount of $\beta$-glucan $[0.70 \mathrm{~g} /(\mathrm{kg} \bullet \mathrm{BW} \bullet \mathrm{d})]$ for 8 weeks. Rats had free access to water and food during this period. Food intake was recorded at 0,3, and $6 \mathrm{w}$, and energy intake was calculated based on the energy density of each diet. Progress and allocation to diet group were shown in Figure 1. Compositions and nutritive components for the experimental diets are shown in Table 2.

Body weights were measured and blood samples collected from the tip of the tail vein at baseline $(0 \mathrm{w})$ and the third $(3 \mathrm{w})$, sixth (6 w) and eighth week (8 w) after a 12-h overnight fast. Serum samples were prepared from blood samples and stored at $-20{ }^{\circ} \mathrm{C}$ until analysis. Fecal samples were collected and stored $-20{ }^{\circ} \mathrm{C}$ until analysis. Animals were sacrificed after blood sample collection at $8 \mathrm{w}$. The epididymal fat pad was carefully dissected, washed in chilled saline solution and weighed. Liver and colonic contents were 
also carefully collected. These samples were immediately frozen in liquid nitrogen after collection and stored at $-70^{\circ} \mathrm{C}$ until analysis. Experiments were conducted following the Guidelines for Animal Experimentation of biological/pharmacological research laboratories. This study was approved by the the Animal Experiment Committee of China (Henan Association for laboratory animal sciences, Zhengzhou).

\subsection{Biochemical Assay and ELISA Assay of Serum}

Biochemical assay kits (BioSino Bio-technology and Science Inc., Beijing, China) and ELISA assay kits (USA) were used to determine the levels of triacylglycerol (TG), total cholesterol (TC), high-density lipoprotein cholesterol (HDL-C), endotoxin (ET) and tumor cell necrosis factor- $\alpha(\mathrm{TNF}-\alpha)$ in serum according to the manufacturer's instructions.

2.5 Determination of lipid content in fecal

Fecal sample collected from each group were dried and $1 \mathrm{~g}$ of dry fecal samples were extracted with $20 \mathrm{~mL}$ of chloroform-methanol $(1: 1, \mathrm{~V} / \mathrm{V})$ at $80{ }^{\circ} \mathrm{C}$ for $1.5 \mathrm{~h}$. After centrifugation (3000 rpm, $15 \mathrm{~min}$ ), the supernatant was collected and dried.

2.6 Histomorphology of Epididymal Adipose Tissue

Epididymal adipose tissue was fixed in $10 \%$ buffered formalin for $48 \mathrm{~h}$ and then processed with tissue processors (BT-300A Dehydrator, CS-V Spreading machine and ZHB1-ZT-HB Baking machine from JinHua YiDi Medical Appliance Co., Ltd., HESTION Embedded machine from TexLab Precision Instruments Co., Ltd., YD1508R Slicer from Shanghai Leica Instruments Co., Ltd.) and tissue sections were prepared 
and stained with hematoxylin, as previously described (Shinnick, Longacre, \& Ink, , 1998). Histopathologic examination was performed under a light microscope (OlympusBX51 Microscopy from Japan), and the fat cells were observed with $10 \times 40$ magnification).

2.7 Quantification of TNF- $\alpha$ Gene Expression in Liver and Adipose Tissue

Total RNA was extracted from liver tissue and epididymal adipose tissue using Trizol Reagent (Invitrogen, Carlsbad, CA, USA) according to the manufacturer's instructions. Then, total RNA was converted to complementary DNA (cDNA) using the High Capacity cDNA Reverse Transcription kit (Applied Biosystems, Foster City, CA, USA). Quantification of gene expression was measured using a 7300 Real Time PCR System (Applied Biosystems). The following primers were used: TNF- $\alpha$ forward: 5'CTGTAGCCCACGTCGTAGC-3'; TNF- $\alpha$ reverse: 5'-TTGAGATCCATGCCGTTG-3'; $\beta$-actin forward: F: 5'-CCACAGCTGAG AGGGAAATC-3'; $\beta$-actin reverse: 5'AAGGAAGGCTGGAAAAGAGC-3'. The relative amount of each gene was calculated using the $2^{-\Delta \Delta \mathrm{CT}}$ method.

2.8 Colonic Microbial Community Analysis using Illumina HiSeq Platforms

Genomic DNA from each colonic sample was extracted using the E.N.Z.A. ${ }^{\circledR}$ Stool DNA Isolation Kit (Omega Bio-tek, USA) and evaluated by measuring the OD value at the wavelengths of $260 \mathrm{~nm}$ and $280 \mathrm{~nm}$. Only qualified genomic DNA samples (Stripes were clear; $\left.\mathrm{OD}_{260} / \mathrm{OD}_{280}=1.8 \sim 2.0\right)$ were selected. Amplification of the $16 \mathrm{~S}$ rRNA gene V3 region was performed as previously described (Yin, Peng, \& Zhao, 2013). The bacterial 
universal primers $\mathrm{F}$ (5' -ATTACCGCGGCTGCTGG-3') and R (5'CGCCCGCCGCGCGCGGCGGGCGGGGCGGGGGCACGGGGGGCCTACGGGAGG

CAGCAG-3') were used. Sequencing the PCR amplicons was conducted by Sangon Biotech (Shanghai, China) using the Illumina HiSeq platforms.

Only high-quality sequences were clustered to obtain representative unique sequences. Unique sequences were then subjected to an RDP classifier to determine phylogeny. Operational taxonomy units (OTUs) were classified with Distance-Based OTU and Richness. Microbiota diversity was assessed with Rarefaction analysis and the Shannon diversity index. Principal component analysis (PCA) was performed to provide an overview of gut microbial dynamics in response to HFD and oat product treatments.

\subsection{Colonic SCFA Measurements}

Frozen colonic contents $(0.1 \sim 0.2 \mathrm{~g})$ were diluted with $2 \mathrm{ml}$ ice-cold physiological saline and $1 \mathrm{ml} 50 \% \mathrm{H}_{2} \mathrm{SO}_{4}$ solution. The contents were mixed with a vortex. Then, $2 \mathrm{ml}$ ether was added to the solution to extract SCFA (Jie, Bang-Yao, \& Ming-Jie, 2000). Acetic acid, propionic acid, iso-butyric acid and butyric were used as standards, and crotonic acid was used as an internal standard. The analysis was performed using a GC-14A gas chromatograph equipped with a flame ionization detector (Shimadzu Corp, Kyoto, Japan) (Shen et al., 2012). However, a $30 \mathrm{~m} \times 0.53 \mathrm{~mm}$ ID fused silica capillary column (PEG$20 \mathrm{M}$ stationary phase) was used, and nitrogen was the carrier gas with a flow rate of 3 $\mathrm{mL} / \mathrm{min}$. The column temperature was $80^{\circ} \mathrm{C}$, and the detector temperature was $240{ }^{\circ} \mathrm{C}$. 


\subsection{Statistical Analysis}

Data from the control and other experimental groups were analyzed with the SPSS 17.0

program using one-way ANOVA. Differences among groups were evaluated for significance by the Tukey post hoc test. $p<0.05$ was considered significantly different. The results are presented as the mean \pm standard deviation $(\mathrm{X} \pm \mathrm{SD})$. Correlations between gut microbial composition (PCA coordinate scores) and individual host parameters, including obesity, lipid levels and inflammation, were identified using Spearman's correlation. Correlations were considered significant when $\mathrm{p}<0.05$.

3 Results

3.1 Nutritional Components and Physicochemical Characteristics of Three Oat Products and Different Diets.

Nutritional components and physicochemical characteristics of oat products were related to the metabolism of DIO rats. The main chemical analysis of oat products before the experiment is listed in Table 1 . OB was rich in total dietary fiber, $\beta$-glucan and resistant starch, which are all beneficial for anti-obesity and improving intestinal flora. However, OB exhibited the highest water-retention, swelling capacity and apparent viscosity. The $\mathrm{M}_{\mathrm{w}}$ of purified $\beta$-glucan samples from $\mathrm{OM}$, OF and OB were $1.74 \times 10^{5}, 5.81 \times 10^{5}$ and $8.20 \times 10^{5} \mathrm{~g} / \mathrm{moL}$, respectively. Nutritional components of normal chow, HFD and HFD supplemented with oat products were also analyzed (Table 2.). HFD containing OF was rich in total dietary fiber, while HFD containing OB was rich in resistant starch. 
3.2 Oat Products Attenuate Features of Obesity, Dyslipidemia and Inflammation in DIO Rats

Compared with rats in the NC group, rats fed with the HFD had higher body weight (Figure 2A) and epididymal fat weight (Figure 2B), and developed hallmark features of dyslipidemia, including elevated serum TC (Figure 2C) and TG (Figure 2D) levels and a reduced HDL-C/TC ratio (Figure 2E). Dietary supplementation with oat products significantly attenuated HFD-induced overweight and fat accumulation despite no reduction in energy intake and no increase in fecal lipid content (Figure 2F and 2G). In addition, all oat products significantly reduced serum TC and TG levels and increased the HDL-C/TC ratio $(p<0.05)$ of DIO rats, with OB and OF appearing to have better effects compared with OM.

We measured serum endotoxin (ET) and serum TNF- $\alpha$ to evaluate the anti-inflammatory effects of three oat products. As shown in Figure $2 \mathrm{H}$ and 2I, during the experiment, each oat product significantly decreased serum ET and TNF- $\alpha$ levels, which were elevated by the HFD in DIO rats. The mean epididymal adipocyte size of DIO rats was 2.49 times (Figure $2 \mathrm{~J}$ and $2 \mathrm{~K}$ ) as large as that of rats in $\mathrm{NC}$ group. The adipocyte size of rats in all oat product groups was smaller than that in MC group, especially for OB group. HFD also increased TNF- $\alpha$ mRNA expression levels in both epididymal adipose tissue and liver (Figure $2 \mathrm{~L}$ and $2 \mathrm{M}$ ). The TNF- $\alpha$ expression level of rats in oat products group was comparative lower than that in DIO rats. 
In summary, these results indicated that the three oat products mitigate HFD-induced obesity (body weight and epididymal fat accumulation), dyslipidemia (serum TC, TG and HDL-C/TC levles) and inflammation (adipocyte size, serum ET and TNF-a levels and TNF-a mRNA expression levels in adipose and liver), and that OB was more effective compared with either OM or OF containing similar amounts of $\beta$-glucan.

\subsection{Oat Products Change the Overall Structure of Gut Microbiota in DIO Rats.}

Fourteen different phyla were assigned by the RDP classifier (Figure 3A and Table S1). The dominant three phyla were Bacteroidetes, Firmicutes and Proteobacteria. As shown in Figure 3B, 3C and 3D, the HFD induced decreases in the abundance of Bacteroidetes and the Bacteroidetes/ Firmicutes ratio (B/F); however, it had no significant effect on the abundance of Firmicutes. Rats in all the three oat products groups had higher level in B/F ratio and lower level in abundance of Firmicutes than DIO rats; of which, rats in OB and OM groups also had higher abundance in Bacteroidetes than DIO rats. It is worth noting that Acidobacteria existed only in oat product groups after the experiment, especially in the OB group (Figure 3E). Besides, bacterial taxa information (species, genera, families and phyla) and the direction of modulation were displayed in the Figure 4A, 4B, 4C and 4D, using heat maps.

We used the richness rarefaction analysis (Figure 5A), Shannon rarefaction analysis (Figure 5B) and principle components analysis to provide an overview of the changes in gut microbiota structure from rats in each group. Community diversity was assessed 
through the Richness Curve and Shannon Index. The Richness Curve and Shannon Index varied greatly between the NC group and MC group, and no oat products narrowed the difference. The PCA scores clearly separated the MC group from the NC group with the three oat product groups distributed in between (Figure 5C), and there was obvious overlapping between the $\mathrm{NC}$ group and $\mathrm{OB}$ group.

These results demonstrated that each of the three oat products shifted the overall structure of gut microbiota in DIO rats toward that of rats in the NC group.

3.4 Overall Structure of Gut Microbiota Correlates to Features of Obesity, Dyslipidemia and Inflammation.

Spearman's correlation analysis was used to determine the associations between the overall structure of gut microbiota represented by PCA coordinates and obesity-related metabolic disorders. As shown in Table 3, there were positive but not significant correlations between gut microbiota structural changes along P1 and features of obesity (body weight and epididymal fat weight), dyslipidemia (TC, TG and HDL-C/TC) and inflammation (serum ET and TNF- $\alpha$, liver TNF- $\alpha$ mRNA and adipocyte TNF- $\alpha$ mRNA). In contrast, gut microbiota structural changes along P2 were negatively correlated with these features. In addition, changes along P2 were significantly associated with serum TC, TG, ET, TNF- $\alpha$ levels, liver TNF- $\alpha$ mRNA expression and adipocyte TNF- $\alpha$ mRNA expression.

3.5 Oat Products Change Colonic SCFAs 
The concentrations of colonic SCFAs were measured, which included acetate, ptopionate, isobutyrate and butyrate. The total SCFA concentration was calculated as the sum of these four SCFAs. The HFD significantly reduced the total concentration of colonic SCFAs; however, the three oat products increased the concentration to an even higher than normal level (Table 4). Rats in the OB group had the highest colonic SCFAs concentration. However, the HFD changed the SCFAs pattern when compared with NC, and $\mathrm{OB}$ restored it, whereas $\mathrm{OM}$ and $\mathrm{OF}$ did not. As shown, the SCFA ratio (acetate:propionate:isobutyrate:butyrate) for each group was approximately 61:22:4:13 (NC), 66:18:2:14 (MC), 67:17:1:14 (OM), 67:18:2:13 (OF), and 63:21:1:15(OB).

\section{Discussion}

Oat products are becoming increasing popular due to their anti-obesity (Handavani, 2012) and prebiotic effects (Shen et al., 2012). This study used a controlled design using HFDinduced obesity SD rats to examine physiological nutrition. After an 8-week administration of oat products, body weight gain and epididymal fat accumulation in rats were inhibited and the serum TC levels, TG levels and HDL-C/TC ratio were improved. These were consistent with previous studies reporting that incorporating oat products into the diet causes a modest reduction in weight gain and in blood cholesterol levels (Ji-Lin, Ying-ying, \& Lin, 2014; Shinnick et al., 1988). When using the same percentage of $\beta$-glucan, the effects from the diet containing OB were the best, which probably related to the high apparent viscosity of $\mathrm{OB}$ and high $\mathrm{M}_{\mathrm{w}}$ of $\beta$-glucan derived from $\mathrm{OB}$. A large increase in 
the mean adipocyte size of DIO rats was observed. Adipocytes are known to release a variety of factors that may contribute to the proinflammatory state that is characteristic for obesity (Dandona, Aljada, \& Bandyopadhyay, 2004). TNF- $\alpha$ was reported to be positively correlated with adipocyte size (Skurk, Alberti-Huber, \& Herder, 2007). Therefore,we next examined serum TNF- $\alpha$ levels and TNF- $\alpha$ mRNA expression levels in adipocytes and liver, and the results showed that both serum TNF- $\alpha$ levels and TNF- $\alpha$ mRNA expression were elevated in DIO rats and declined significantly after administration of oat products. Excessive TNF- $\alpha$ can increase the development of insulin resistance associated with dietary obesity (Hotamisligil, 1999). Lipopolysaccharide (LPS), a major component of the outer membrane of Gram-negative bacteria (Wright, Ramos, \& Tobias, 1990), is the principal active agent in the pathogenesis of endotoxin (ET) shock. Endotoxin shock is a triggering factor for expression of TNF- $\alpha$ (Karaghiosoff et al., 2003). . Oat products reduced serum ET levels that were elevated by HFD, suggesting that the effects of oat products on TNF- $\alpha$ expression may partially be due to their modulation of gut microbiota.

The view that ingestion of an oat-based diet alters the gut environment is supported in this study by the characterized gut microbiota composition. Increases in the abundance of Bacteroidetes and the $\mathrm{B} / \mathrm{F}$ ratio were observed in oat product groups and are consistent with Parnel et al.'s research on prebiotic fiber (Parnell, \& Reimer, 2012). Previous studies has revealed that changes in the relative abundance of the two dominant bacterial divisions, the Bacteroidetes and the Firmicutes, were always associated with a switch in the 
metabolic potential of the microbiota in the gut microbiome of obesity models and increased their capacity to harvest energy from the diet (Turnbaugh et al., 2006). PCA analysis revealed that oat products induced significant changes in the overall gut microbiota structure. Bacteria in the Acidobacteria phylum were detected by $16 \mathrm{~S}$ rRNA gene-based surveys in a wide variety of environments; however, little is known about their physiology or ecological activity (Barns, Cain, \& Sommerville, 2007). In this study, it is worth noting that the Acidobacteria only existed in oat product groups and were positively correlated (not significant) with gut SCFA concentrations. This suggested that Acidobacteria might be a biomarker for an acidic gut environment, which remains to be further researched. SCFA are the principal fermentation products from substrates broken down by gut microbiota (Simon et al., 2007). Previous studies suggested that increased production of SCFAs may affect lipogenesis and secretion of peptide YY (PYY), which could regulate appetite and inhibit food intake (Degen, Oesch, \& Casanova, 2005). Our data showed that oat products increased the total SCFA concentration, which was reduced by a HFD, especially with OB. Among the studied SCFAs, the proportion of acetate decreased, while the proportion of propionate and butyrate increased compared with the MC group. Previous reported found that acetate contributes to lipid and cholesterol synthesis in the liver, while propionate inhibits the effects of acetate and lowers serum cholesterol (Laparra, \& Sanz, 2010). Butyrate was reported to reduce gut mucosal permeability, increasing transepithelial electrical resistance, and impeding PEG 
translocation in heat-damaged rat colon (Conterno, Fava, Viola, \& Tuohy, 2011). Dietary fiber and resistant starch that escape digestion in the small intestine and are fermented in the gut are generally recognized as the main components that could affect gut microbiota composition and SCFA concentrations (Nielsen, Theil, \& Purup, 2015). The results from chemical analyses showed that the sum of total dietary fiber and resistant contents from three experimental diets were $9.87 \%$ (diet containing OB), 9.28\% (diet containing OM) and $9.28 \%$ (diet containing OF), which may be one explanation for the more promising effects induced by OB on gut microbiota modification and SCFAs production.

We firstly found that changes in the gut microbiota induced by oat products were correlated with obesity related metabolic disorders, especially for serum lipid and inflammation levels in DIO rats. Therefore, a speculation that oat products protect DIO rats from some chronic diseases through modifications of gut microbiota structure was proposed. However, to provide direct evidence for this speculation, a further fecal transplant research is needed.

In conclusion, the three oat products individually attenuate the HFD induced obesity and related metabolic disorders in DIO rats. However, the overall gut microbiota structure was altered by these oat products. OB exhibited the most promising effects on inhibiting weight gain and eipididymal fat accumulation, improving serum lipid and inflammation levels, modifying gut microbiota composition and increasing SCFAs concentration. This new finding from our study compared with previous studies is that changes in gut microbiota 
induced by oat products were correlated with obesity-related metabolic disorders (serum lipid and inflammation levels) more than weight gain and fat accumulation. We anticipated that our results will contribute to the development of oat-based diet food for anti-obesity.

\section{Acknowledgment}

This research was supported by the National Science Foundation of China grant No.31271854.

\section{References}

Barns, S. M., Cain, E. C., \& Sommerville, L. (2007). Acidobacteria phylum sequences in uranium-contaminated subsurface sediments greatly expand the known diversity within the phylum. Applied and Environmental Microbiology, 73, 3113-3116.

Brown, C. D., Higgins, M., \& Donato, K. A. (2000). Body mass index and the prevalence of hypertension and dyslipidemia. Obesity Research, 8, 605-619.

Cani, P. D., Bibiloni, R., \& Knauf, C. (2008). Changes in gut microbiota control metabolic endotoxemia-induced inflammation in high-fat diet-induced obesity and diabetes in mice. Diabetes, 57, 1470-1481.

Conterno, L., Fava, F., Viola, R., \& Tuohy, K. M. (2011). Obesity and the gut microbiota: does up-regulating colonic fermentation protect against obesity and metabolic disease?. 
Genes and Nutrition, 6(3), 241-260.

Dandona, P., Aljada, A., \& Bandyopadhyay, A. (2004). Inflammation: the link between insulin resistance, obesity and diabetes. Trends in immunology, 25, 4-7.

Degen, L., Oesch, S., \& Casanova, M. (2005). Effect of peptide YY 3-36 on food intake in humans. Gastroenterology, 129, 1430-1436.

Everard, A., Belzer, C., \& Geurts, L. (2013). Cross-talk between Akkermansia muciniphilaand intestinal epithelium controls diet-induced obesity. Proceedings of the National Academy of Sciences of the United States of America, 110, 9066-9071.

Guevara-Cruz, M., Tovar, A. R., \& Aguilar-Salinas. (2012). A dietary pattern including nopal, chia seed, soy protein, and oat reduces serum triglycerides and glucose intolerance in patients with metabolic syndrome. Journal of Nutrition, 142, 64-69.

Handayani, D. (2012). Prevention and treatment of high fat diet-induced obesity by dietary intake of shiitake and oat. University of Wollongong.

Hotamisligil, G. S. (1999). The role of TNF $\alpha$ and TNF receptors in obesity and insulin resistance. Journal of Internal Medicine, 245, 621-625.

Laparra, J. M., \& Sanz, Y. (2010). Interactions of gut microbiota with functional food components and nutraceuticals. Pharmacological Research, 61, 219-225.

Liu, Q., Xu, X., \& Zhang, L. (2012). Interaction between polydeoxyadenylic acid and $\beta$ glucan from Lentinus edodes. European Polymer Journal, 48, 1329-1338. 
Jie, Z., Bang-Yao, L., \& Ming-Jie, X. (2000). Studies on the effects of polydextrose intake on physiologic functions in Chinese people. American Journal of Clinical Pathology, 72, 1503-1509.

Ji-Lin, D., Ying-ying, Z., \& Lin, L. (2014). Effect of Oat Soluble and Insoluble $\beta$-glucan on Lipid Metabolism and Intestinal Lactobacillus in High-fat Diet-induced Obese Mice. Journal of Food and Nutrition Research, 2, 510-516.

Karaghiosoff, M., Steinborn, R., Kovarik, P., Kriegshäuser, G., Baccarini, M., Donabauer, B., \& Levy, D. (2003). Central role for type I interferons and Tyk2 in lipopolysaccharideinduced endotoxin shock. Nature Immunology, 4(5), 471-477.

Maki, K. C., Beiseigel, J. M., \& Jonnalagadda, S. S. (2010). Whole-grain ready-to-eat oat cereal, as part of a dietary program for weight loss, reduces low-density lipoprotein cholesterol in adults with overweight and obesity more than a dietary program including low-fiber control foods. Journal of the American Dietetic Association, 110, 205-214.

Nielsen, T. S., Theil, P., \& Purup, S. (2015). Effects of Resistant Starch and Arabinoxylan on Parameters Related to Large Intestinal and Metabolic Health in Pigs Fed Fat Rich Diets. Journal of Agricultural and Food Chemistry, DOI: 10.1021/acs.jafc.5b03372.

Parnell, J. A., \& Reimer, R. A. (2012). Prebiotic fibres dose-dependently increase satiety hormones and alter Bacteroidetes and Firmicutes in lean and obese JCR: LA-cp rats. British Journal of Nutrition, 107, 601-613.

Riesenfeld, C. S., Schloss, P. D., \& Handelsman, J. (2004). Metagenomics: genomic 
analysis of microbial communities. Annual review of genetics, 38, 525-552.

Scott, K. P., Duncan, S. H., \& Flint, H. J. (2008). Dietary fibre and the gut microbiota. Nutrition Bulletin, 33, 201-211.

Shen, R. L., Cai, F. L., \& Dong, J. L. (2011). Hypoglycemic effects and biochemical mechanisms of oat products on streptozotocin-induced diabetic mice. Journal of Agricultural and Food Chemistry, 59, 8895-8900.

Shen, R. L., Dang, X. Y., \& Dong, J. L. (2012). Effects of Oat $\beta$-Glucan and Barley $\beta$ Glucan on Fecal Characteristics, Intestinal Microflora, and Intestinal Bacterial Metabolites in Rats. Journal of Agricultural and Food Chemistry, 60, 11301-11308.

Shinnick, F. L., Longacre, M. J., \& Ink, S. L. (1988). Oat fiber: composition versus physiological function in rats. Journal of Nutrition, 118, 144-151.

Simon, A. H., Peter, R. S., \& Glenn, R. G. (2007). In vitro fermentation of oat and barley derived $\beta$-glicans by human faecal microbiota. FEMS Microbiology Ecology, 64, 482493.

Skurk, T., Alberti-Huber, C., \& Herder, C. (2007). Relationship between adipocyte size and adipokine expression and secretion. Journal of Clinical Endocrinology \& Metabolism, 92, 1023-1033.

Snart, J., Bibiloni, R., \& Grayson, T. (2006). Supplementation of the diet with highviscosity beta-glucan results in enrichment for Lactobacilli in the rat cecum. Applied and Environmental Microbiology, 72, 1925-1931. 
Turnbaugh, P. J., Ley, R. E., \& Mahowald, M. A. (2006). An obesity-associated gut microbiome with increased capacity for energy harvest. Nature, 444, 1027-131.

Veiga, P., Gallini, C. A., \& Beal, C. (2010). Bifidobacterium animalis subsp. lactis fermented milk product reduces inflammation by altering a niche for colitogenic microbes. Proceedings of the National Academy of Sciences of the United States of America, 107, 18132-18137.

Wang, J., Li, Z. Y., \& Jiao, Y. L. (2009). Study on extraction technology and basic characteristics of dietary fiber from persimmon peel. Science and Technology of Food Industry, 4, 258-261.

Wang, J., Tang, H., \& Zhang, C. (2015). Modulation of gut microbiota during probioticmediated attenuation of metabolic syndrome in high fat diet-fed mice. ISME Journal, 9, $1-15$.

Wright, S. D., Ramos, R. A., \& Tobias, P. S. (1990). CD14, a receptor for complexes of lipopolysaccharide (LPS) and LPS binding protein. Science, 249, 1431-1433.

Xu, J., Zhou, C. W., \& Wang, R. Z. (2012). Lipase-coupling esterification of starch with octenyl succinic anhydride. Carbohydrate Polymers, 87, 2137-2144.

Yin, X., Peng, J., \& Zhao, L. (2013). Structural changes of gut microbiota in a rat nonalcoholic fatty liver disease model treated with a Chinese herbal formula. Systematic and Applied Microbiology, 36, 188-196.

Zhang, C., Zhang, M., \& Wang, S. (2010). Interactions between gut microbiota, host 
genetics and diet relevant to development of metabolic syndromes in mice. ISME Journal, 4, 232-241.

\section{Figure Captions}

Figure 1. Progress and allocation to diet group. Abbreviations: SD, Sprague-Dawley; HFD, High-fat Diet; NC, Normal Control Group; DIO, Diet-induced Obesity Model; MC, model control group; OM, oat meal group; OF, oat flour group; OB, high fiber oat bran group.

Figure 2. Oat products attenuated HFD-induced obesity. (A) Body weight, (B) epididymal fat coefficient, (C) serum TC level, (D) serum TG level, (E) HDL-C/TC ratio, (F) energy intake, (G) lipid content in fecal (H) serum ET level, (I) serum TNF-r level, (J) adipose size, $(\mathrm{K})$ epididymal adipose tissue section $(10 \times 40)$, (L) liver TNF- $\alpha$ mRNA expression level, and (M) adipose TNF- $\alpha$ mRNA expression level from rats in each group. Data are presented the mean $\pm \mathrm{SD}$. Values that do not share the same capital letter are significantly different $(p<0.05)$. Abbreviations: $\mathrm{NC}$, normal control group; MC, model control group; $\mathrm{OM}$, oat meal group; OF, oat flour group; OB, high fiber oat bran group; TC, total cholesterol; TG, triglyceride; HDL-C, high density lipoprotein cholesterol; ET, endotoxin; TNF- $\alpha$, tumor necrosis factor $\alpha$. 
Figure 3. Relative abundance of different phyla in the gut microbiota from rats in each group at 8 w. (A) Overall abundance, (B) Bacteroidetes, (C) Firmicutes, (D) Bacteroidetes/Firmicutes ratio, and (E) Acidobacteria. \#represents a significant difference compared with the NC group $(p<0.05)$. *represents a significant difference compared with the MC group $(p<0.05)$. Abbreviations: NC, normal control group; MC, model control group; OM, oat meal group; OF, oat flour group; OB, high fiber oat bran group.

Figure 4. Heatmaps of phylum (A), family (B), genus (C), and species (D). Abbreviations: NC, normal control group; MC, model control group; OM, oat meal group; OF, oat flour group; OB, high fiber oat bran group.

Figure 5. Overall structure of gut microbiota from rats in each group at 8 w. (A) Richness rarefaction analysis, (B) Shannon rarefaction analysis, and (C) PCA analysis. Abbreviations: NC, normal control group; MC, model control group; OM, oat meal group; OF, oat flour group; OB, high fiber oat bran group. 
Table. 1 Nutritional component and physicochemical characteristics of three oat products

\begin{tabular}{|c|c|c|c|}
\hline & $\mathrm{OM}$ & $\mathrm{OF}$ & OB \\
\hline \multicolumn{4}{|l|}{ Nutritional component } \\
\hline Total dietary fiber (\%) & $20.38 \pm 0.05^{\mathrm{b}}$ & $14.15 \pm 0.11^{\mathrm{c}}$ & $29.90 \pm 0.12^{\mathrm{a}}$ \\
\hline Crude protein $(\%)$ & $13.12 \pm 0.07^{\mathrm{a}}$ & $13.60 \pm 0.08^{\mathrm{a}}$ & $11.62 \pm 0.30^{\mathrm{b}}$ \\
\hline Crude fat $(\%)$ & $7.10 \pm 0.11^{\mathrm{a}}$ & $4.58 \pm 0.08^{b}$ & $6.98 \pm 0.17^{\mathrm{a}}$ \\
\hline Crude ash $(\%)$ & $2.02 \pm 0.04^{\mathrm{b}}$ & $1.45 \pm 0.06^{\mathrm{c}}$ & $2.98 \pm 0.10^{\mathrm{a}}$ \\
\hline Total starch (\%) & $50.34 \pm 0.52^{\mathrm{b}}$ & $57.15 \pm 1.57^{\mathrm{a}}$ & $38.90 \pm 0.76^{\mathrm{c}}$ \\
\hline Moisture (\%) & $6.16 \pm 0.05^{\mathrm{c}}$ & $8.53 \pm 0.14^{\mathrm{a}}$ & $7.81 \pm 0.04^{\mathrm{b}}$ \\
\hline$\beta$-Glucan (\%) & $4.15 \pm 0.12^{\mathrm{b}}$ & $1.78 \pm 0.21^{\mathrm{c}}$ & $8.10 \pm 0.66^{\mathrm{a}}$ \\
\hline \multicolumn{4}{|l|}{ Physicochemical characteristics } \\
\hline $\begin{array}{l}\text { Apparent viscosity }(\mathrm{mPa} \cdot \mathrm{s}) \\
25^{\circ} \mathrm{C}, 5 \% \mathrm{M} / \mathrm{M}, \quad 200 \mathrm{rpm}\end{array}$ & $10.33 \pm 0.58^{c}$ & $37.33 \pm 1.34^{\mathrm{b}}$ & $50.00 \pm 2.00^{\mathrm{a}}$ \\
\hline Water-retaining capacity $(\mathrm{g} / \mathrm{g})$ & $3.14 \pm 0.06^{c}$ & $4.28 \pm 0.11^{\mathrm{b}}$ & $5.02 \pm 0.09^{\mathrm{a}}$ \\
\hline Swelling capacity $(\mathrm{mL} / \mathrm{g})$ & $0.4 \pm 0.03^{b}$ & $2.3 \pm 0.11^{\mathrm{a}}$ & $2.4 \pm 0.08^{\mathrm{a}}$ \\
\hline
\end{tabular}

Data are mean $\pm S D(n=3)$. Differences among groups were evaluated for significance by the Tukey post hoc test. Values in the same row that do not share the same lowercase letter are significantly different $(p<0.05)$.

Abbreviations: OM, oat meal group; OF, oat flour group; OB, high fiber oat bran group. 
Table. 2 Formula, nutritional components and energy density of different diets

\begin{tabular}{|c|c|c|c|c|c|}
\hline & \multicolumn{5}{|c|}{ Diet $(\mathrm{g} / 100 \mathrm{~g}$ dried feed $)$} \\
\hline & Basic diet* & $\begin{array}{l}\text { High-fat } \\
\text { diet }\end{array}$ & $\begin{array}{c}\text { Experimental } \\
\text { diet I }\end{array}$ & $\begin{array}{c}\text { Experimental } \\
\text { diet II }\end{array}$ & $\begin{array}{c}\text { Experimental } \\
\text { diet III }\end{array}$ \\
\hline Barley flour & 20.0 & 11.6 & 7.30 & 1.60 & 9.40 \\
\hline Soybean flour & 20.0 & 11.6 & 7.30 & 1.60 & 9.40 \\
\hline Corn flour & 32.0 & 18.6 & 11.7 & 2.60 & 15.0 \\
\hline $\begin{array}{l}\text { Dehydrated } \\
\text { vegetable }\end{array}$ & 10.0 & 5.80 & 3.70 & 0.80 & 4.70 \\
\hline Fishmeal & 10.0 & 5.80 & 3.70 & 0.80 & 4.70 \\
\hline Bonemeal & 5.00 & 2.90 & 1.80 & 0.40 & 2.40 \\
\hline Salt & 2.00 & 1.20 & 0.70 & 0.20 & 0.90 \\
\hline Yeast & 1.00 & 0.60 & 0.40 & 0.10 & 0.50 \\
\hline $\begin{array}{l}\text { Egg yolk } \\
\text { powder }\end{array}$ & -1 & 10.0 & 10.0 & 10.0 & 10.0 \\
\hline Sugar & - - & 5.00 & 5.00 & 5.00 & 5.00 \\
\hline Peanuts & - & 4.00 & 4.00 & 4.00 & 4.00 \\
\hline Lard & - & 13.0 & 13.0 & 13.0 & 13.0 \\
\hline Milk powder & - & 10.0 & 10.0 & 10.0 & 10.0 \\
\hline $\mathrm{OM}$ & - - & - & 21.4 & - - & - \\
\hline OF & - & - - & - & 49.8 & - \\
\hline OB & - - & - & - & - - & 11.0 \\
\hline & & Nutriti & hal component & & \\
\hline $\begin{array}{c}\text { Total dietary } \\
\text { fiber }\end{array}$ & $4.72 \pm 0.07^{\mathrm{c}}$ & $2.81 \pm 0.10^{\mathrm{d}}$ & $6.60 \pm 0.13^{b}$ & $7.11 \pm 0.18^{\mathrm{a}}$ & $6.48 \pm 0.09^{b}$ \\
\hline Crude protein & $24.0 \pm 1.77^{\mathrm{a}}$ & $17.1 \pm 1.05^{\mathrm{b}}$ & $14.7 \pm 1.45^{b}$ & $12.0 \pm 0.60^{c}$ & $15.7 \pm 0.98^{b}$ \\
\hline Crude fat & $4.85 \pm 0.22^{\mathrm{b}}$ & $20.9 \pm 1.45^{\mathrm{a}}$ & $20.8 \pm 0.91^{\mathrm{a}}$ & $20.5 \pm 1.09^{\mathrm{a}}$ & $21.2 \pm 1.01^{\mathrm{a}}$ \\
\hline Crude starch & $53.6 \pm 1.76^{\mathrm{a}}$ & $45.0 \pm 2.01^{\mathrm{b}}$ & $44.1 \pm 1.67^{\mathrm{b}}$ & $46.7 \pm 2.23^{b}$ & $43.3 \pm 2.11^{\mathrm{b}}$ \\
\hline Crude ash & $6.80 \pm 0.23^{\mathrm{b}}$ & $7.34 \pm 0.12^{\mathrm{a}}$ & $7.32 \pm 0.26^{\mathrm{a}}$ & $5.72 \pm 0.11^{\mathrm{c}}$ & $6.92 \pm 0.18^{b}$ \\
\hline
\end{tabular}




\begin{tabular}{cccccc}
\hline mosisture & $6.55 \pm 0.21^{\mathrm{e}}$ & $6.90 \pm 0.18^{\mathrm{d}}$ & $7.55 \pm 0.11^{\mathrm{a}}$ & $7.33 \pm 0.08^{\mathrm{b}}$ & $7.11 \pm 0.13^{\mathrm{c}}$ \\
$\begin{array}{c}\beta \text {-Glucan } \\
\text { Resistant }\end{array}$ & $0.39 \pm 0.07^{\mathrm{b}}$ & $0.24 \pm 0.03^{\mathrm{c}}$ & $1.05 \pm 0.07^{\mathrm{a}}$ & $0.96 \pm 0.06^{\mathrm{a}}$ & $0.98 \pm 0.06^{\mathrm{a}}$ \\
starch & $4.22 \pm 0.11^{\mathrm{a}}$ & $2.31 \pm 0.16^{\mathrm{d}}$ & $2.68 \pm 0.09^{\mathrm{c}}$ & $1.16 \pm 0.10^{\mathrm{e}}$ & $3.39 \pm 0.21^{\mathrm{b}}$ \\
& \multicolumn{5}{c}{$\mathrm{kJ} / 100 \mathrm{~g}$ feed $(\times 10)$} \\
Energy density & 159 & 192 & 192 & 192 & 192 \\
\hline
\end{tabular}

*The basic diet was supplied by Laboratory Animal Centre of Henan Province.

Data are mean \pm SD $(n=3)$. Differences among groups were evaluated for significance by the Tukey post hoc test. Values in the same row that do not share the same lowercase letter are significantly different $(\mathrm{p}<0.05)$.

Abbreviations: OM, oat meal group; OF, oat flour group; OB, high fiber oat bran group. 
Table. 3 Spearman's correlation between gut microbiota composition represented by the first two coordinates of weighted UniFrac PCA and HFD induced obesity and hyperlipemia parameters

\begin{tabular}{ccccc}
\hline & \multicolumn{2}{c}{$\mathrm{P} 1$} & & \multicolumn{2}{c}{$\mathrm{P} 2$} \\
\cline { 2 - 5 } & $\mathrm{r}$ & $p$ & $\mathrm{r}$ & $p$ \\
\hline Body weight & 0.60 & 0.285 & -0.80 & 0.104 \\
Epididymal fat weight & 0.60 & 0.285 & -0.80 & 0.104 \\
TC* & 0.70 & 0.188 & -0.90 & 0.037 \\
TG* $^{*}$ & 0.70 & 0.188 & -0.90 & 0.037 \\
HDL-C/TC & 0.00 & 1.000 & 0.60 & 0.285 \\
ET* & 0.60 & 0.285 & -0.80 & 0.037 \\
TNF- $\alpha *$ & 0.70 & 0.188 & -0.90 & 0.037 \\
Liver TNF- $\alpha$ mRNA* & 0.70 & 0.188 & -0.90 & 0.037 \\
Adipocyte TNF- $\alpha$ & & & & 0.037 \\
mRNA* & 0.70 & 0.188 & -0.90 & \\
\hline
\end{tabular}

* present a significant correlation with $\mathrm{P} 2$.

Correlations were identified using Spearman's correlation. Correlations were considered significant when $p<0.05$.

Abbreviations: NC, normal control group; MC, model control group; OM, oat meal group; OF, oat flour group; OB, high fiber oat bran group; TC, total cholesterol; TG, triglyceride; HDL-C, high density lipoprotein cholesterol; ET, endotoxin; TNF- $\alpha$, tumor necrosis factor $\alpha$. 
Table. 4 Changes in colonic SCFAs of rats in each at week 8 ( $\mathrm{mmol} / \mathrm{g}$ colonic digesta)

\begin{tabular}{cccccc}
\hline & Acetate & Propionate & Isobutyrate & Butyrate & Total SCFA \\
\hline NC & $4.71 \pm 0.22^{\mathrm{d}}$ & $1.69 \pm 0.43^{\mathrm{bc}}$ & $0.28 \pm 0.02^{\mathrm{ab}}$ & $0.99 \pm 0.09^{\mathrm{c}}$ & $7.67 \pm 0.31^{\mathrm{d}}$ \\
MC & $2.81 \pm 0.13^{\mathrm{e}}$ & $0.76 \pm 0.08^{\mathrm{d}}$ & $0.10 \pm 0.01^{\mathrm{d}}$ & $0.61 \pm 005^{\mathrm{d}}$ & $4.28 \pm 0.67^{\mathrm{e}}$ \\
OM & $9.37 \pm 0.56^{\mathrm{b}}$ & $2.40 \pm 0.21^{\mathrm{b}}$ & $0.19 \pm 0.04^{\mathrm{bc}}$ & $2.01 \pm 0.21^{\mathrm{a}}$ & $13.99 \pm 0.58^{\mathrm{b}}$ \\
OF & $8.01 \pm 0.11^{\mathrm{c}}$ & $2.21 \pm 0.50^{\mathrm{bc}}$ & $0.22 \pm 0.05^{\mathrm{abc}}$ & $1.39 \pm 0.33^{\mathrm{b}}$ & $11.88 \pm 1.01^{\mathrm{c}}$ \\
OB & $11.95 \pm 1.01^{\mathrm{a}}$ & $3.92 \pm 0.33^{\mathrm{a}}$ & $0.22 \pm 0.01^{\mathrm{bc}}$ & $2.90 \pm 0.78^{\mathrm{a}}$ & $18.99 \pm 0.88^{\mathrm{a}}$ \\
\hline
\end{tabular}

Data are mean $\pm S D(n=10)$. Differences among groups were evaluated for significance by the Tukey post hoc test. Values in the same row that do not share the same lowercase letter are significantly different $(p<0.05)$.

Abbreviations: SCFA, short chain fatty acid; NC, normal control group; MC, model control group; OM, oat meal group; OF, oat flour group; OB, high fiber oat bran group. 
Figure 1. Progress and allocation to diet group

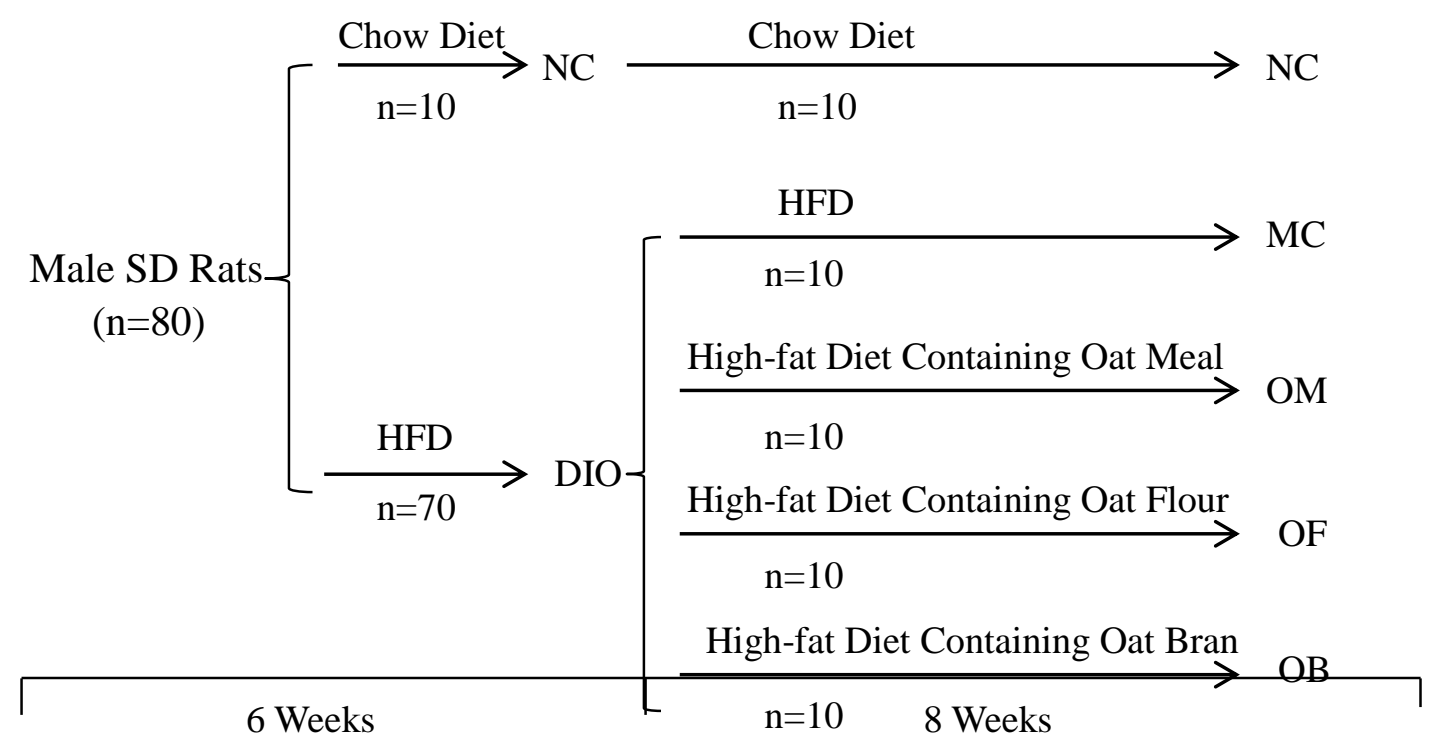


Figure 2. Oat products attenuated HFD induced obesity.

(A)

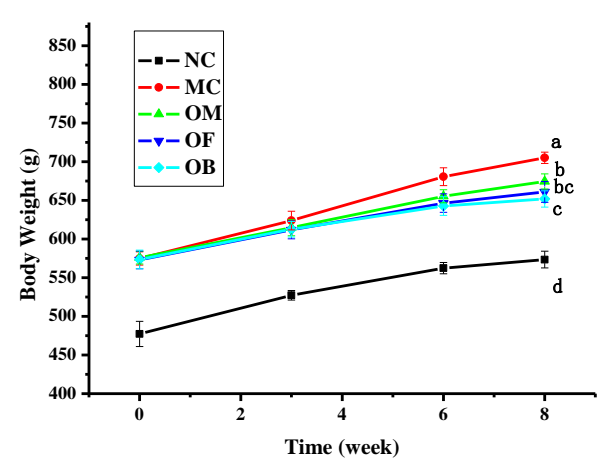

(D)

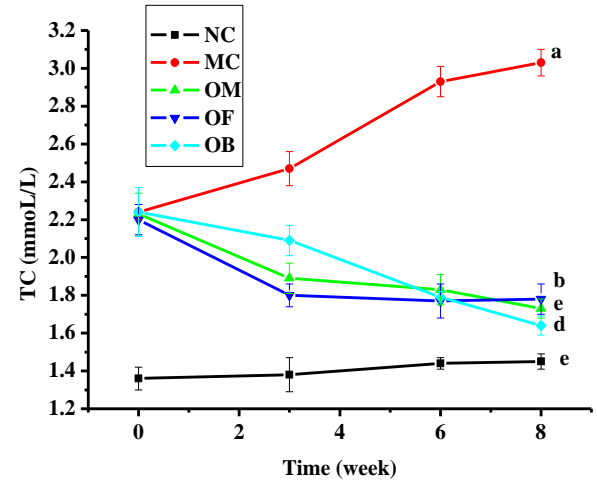

(E)

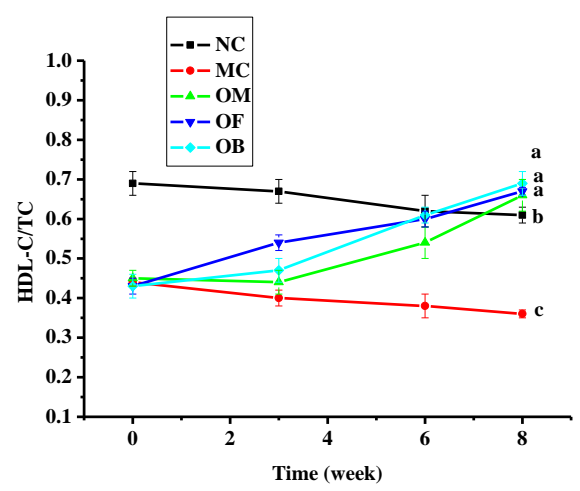

(G)
(B)

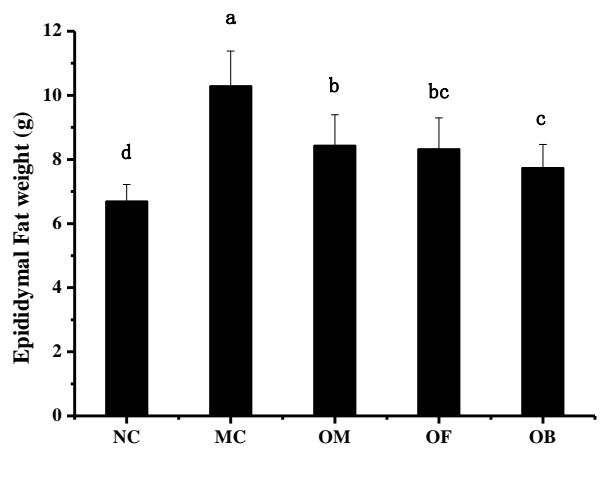

(C)

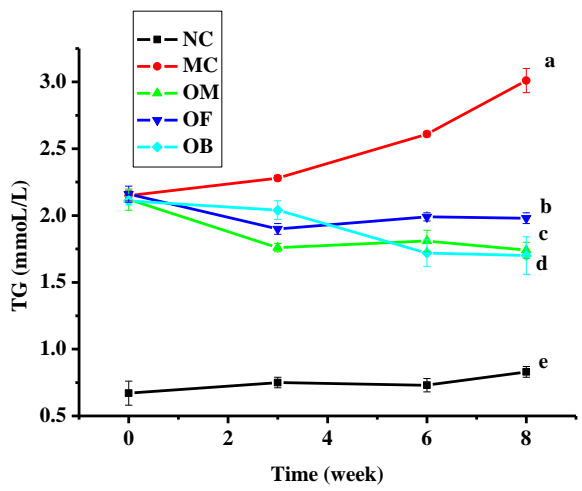

(F)

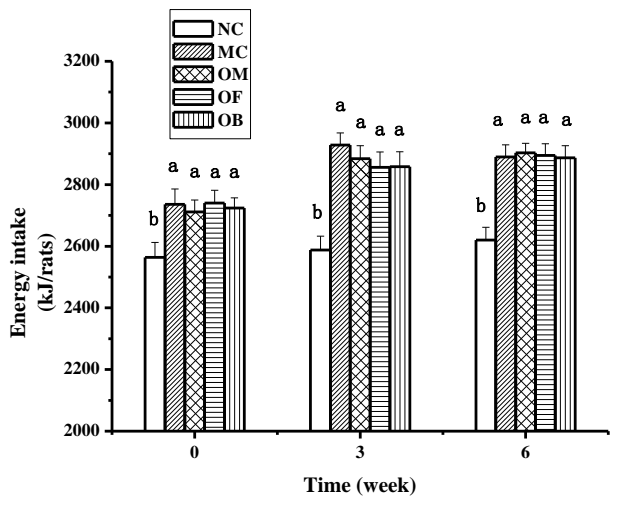

(H) 

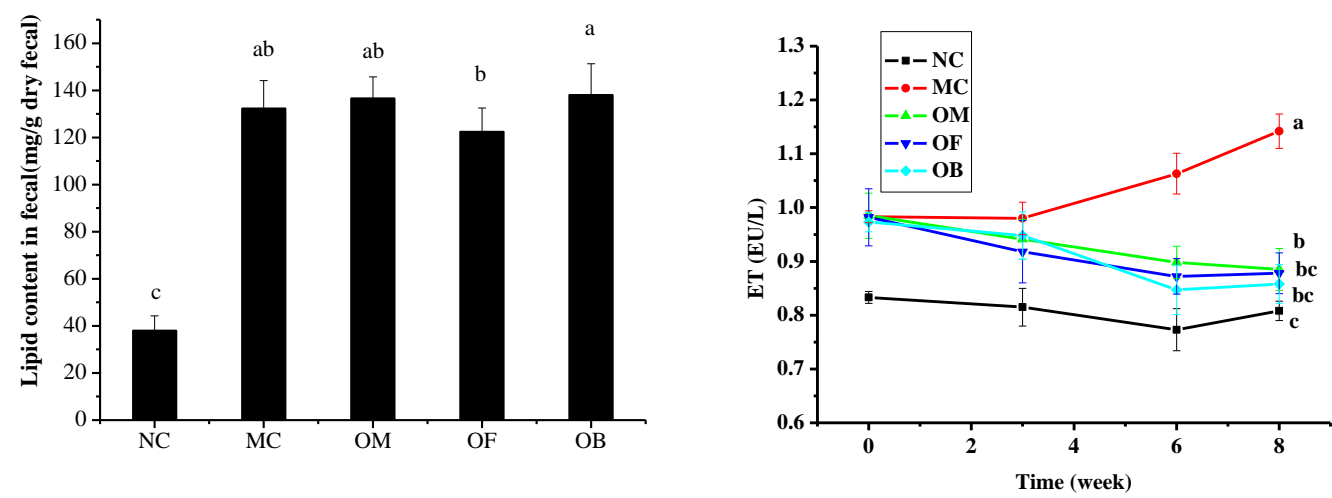

(I)

(J)
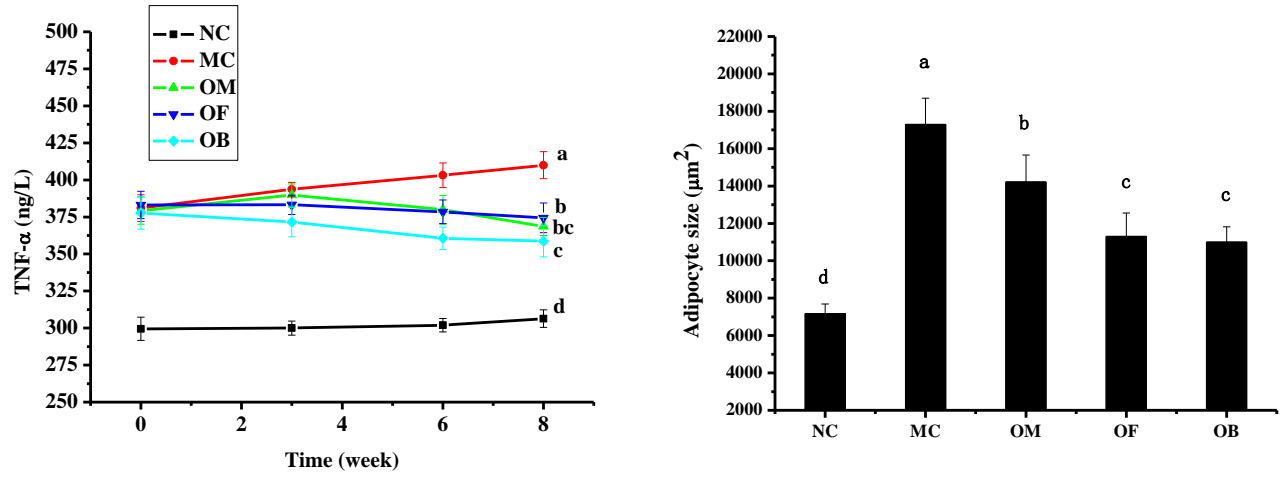

(K)
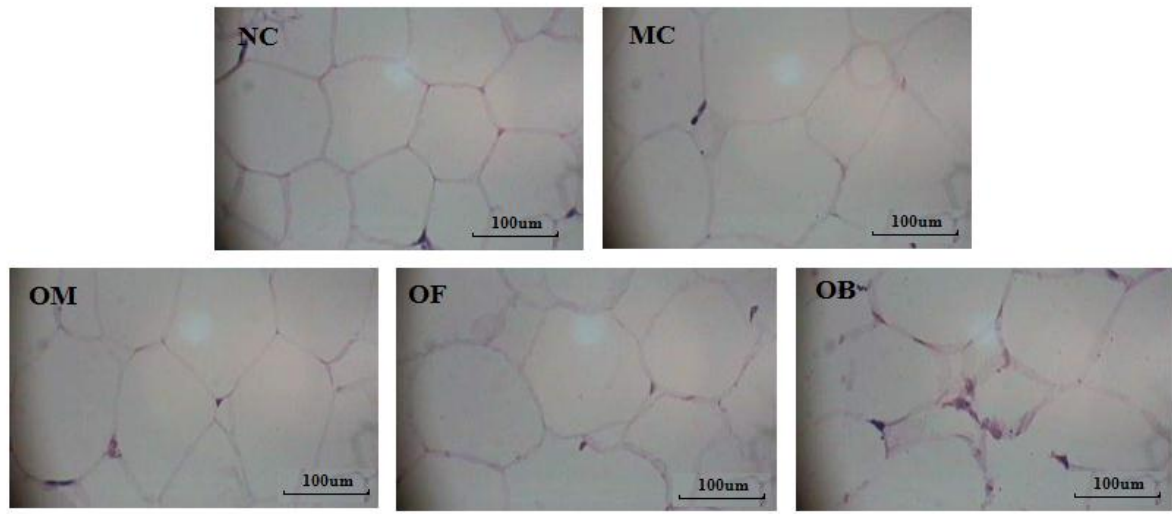

(L)

(M)
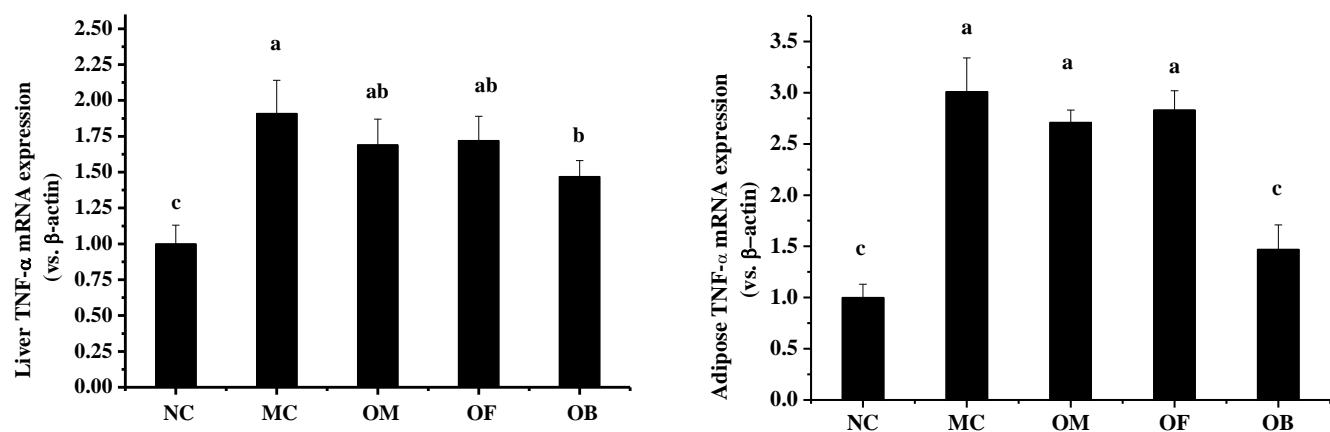
Figure 3. Relative abundance of different phyla in the gut microbiota of rats in each group at $8 \mathrm{w}$.

(A)

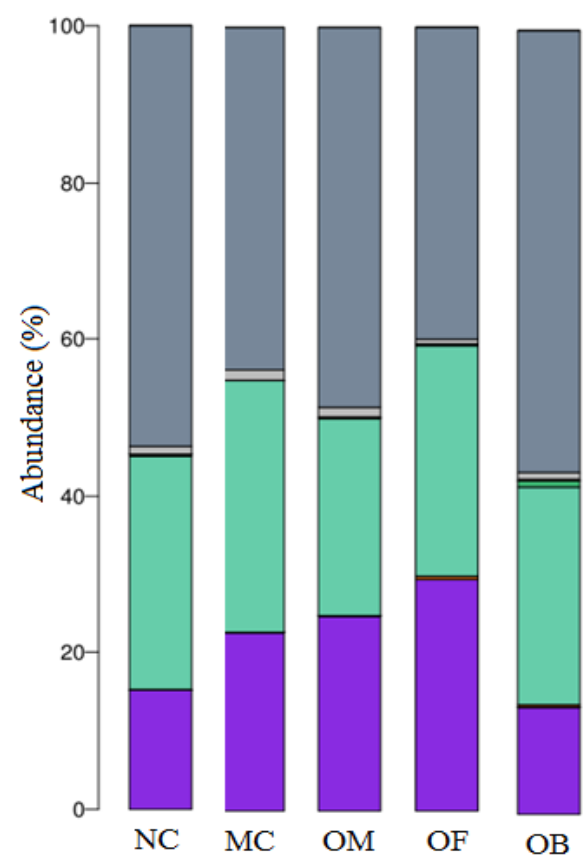

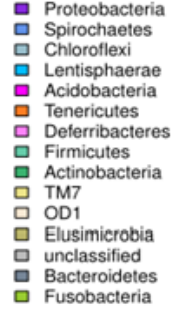

(B)

(C)
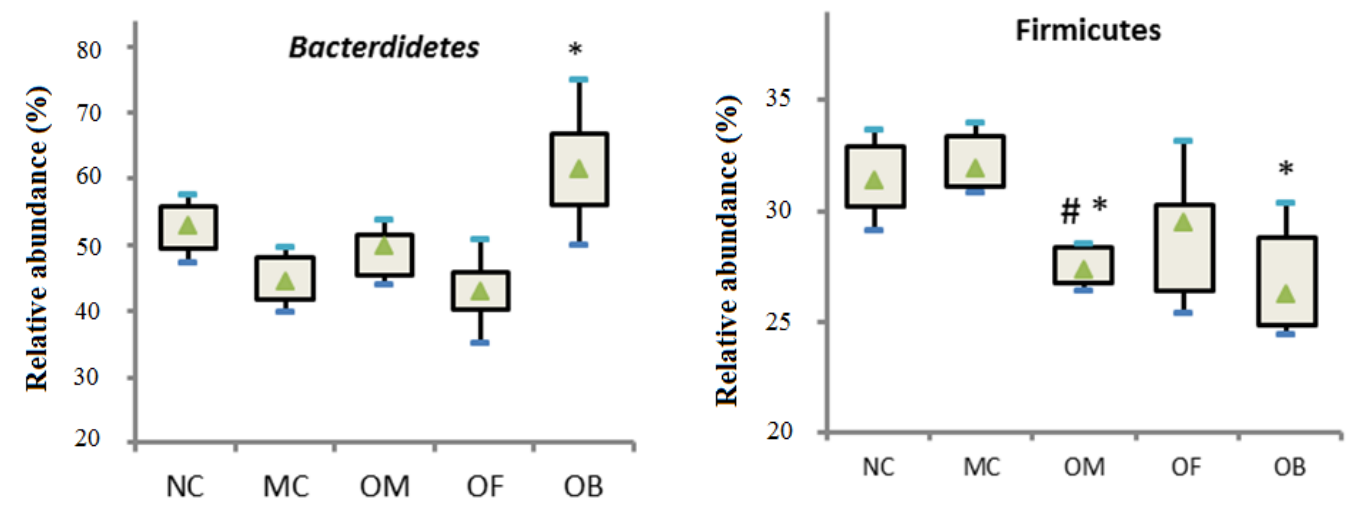

(D)

(E) 

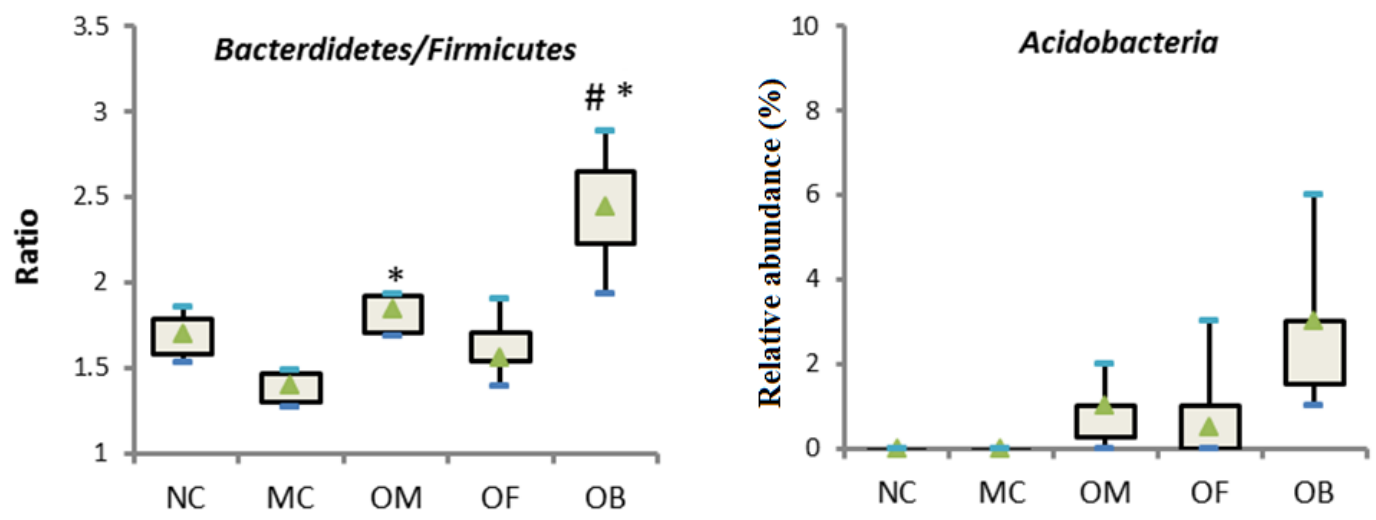
Figure 4. Heatmaps of phylum (A), family (B), genus (C), and species (D).

(A)

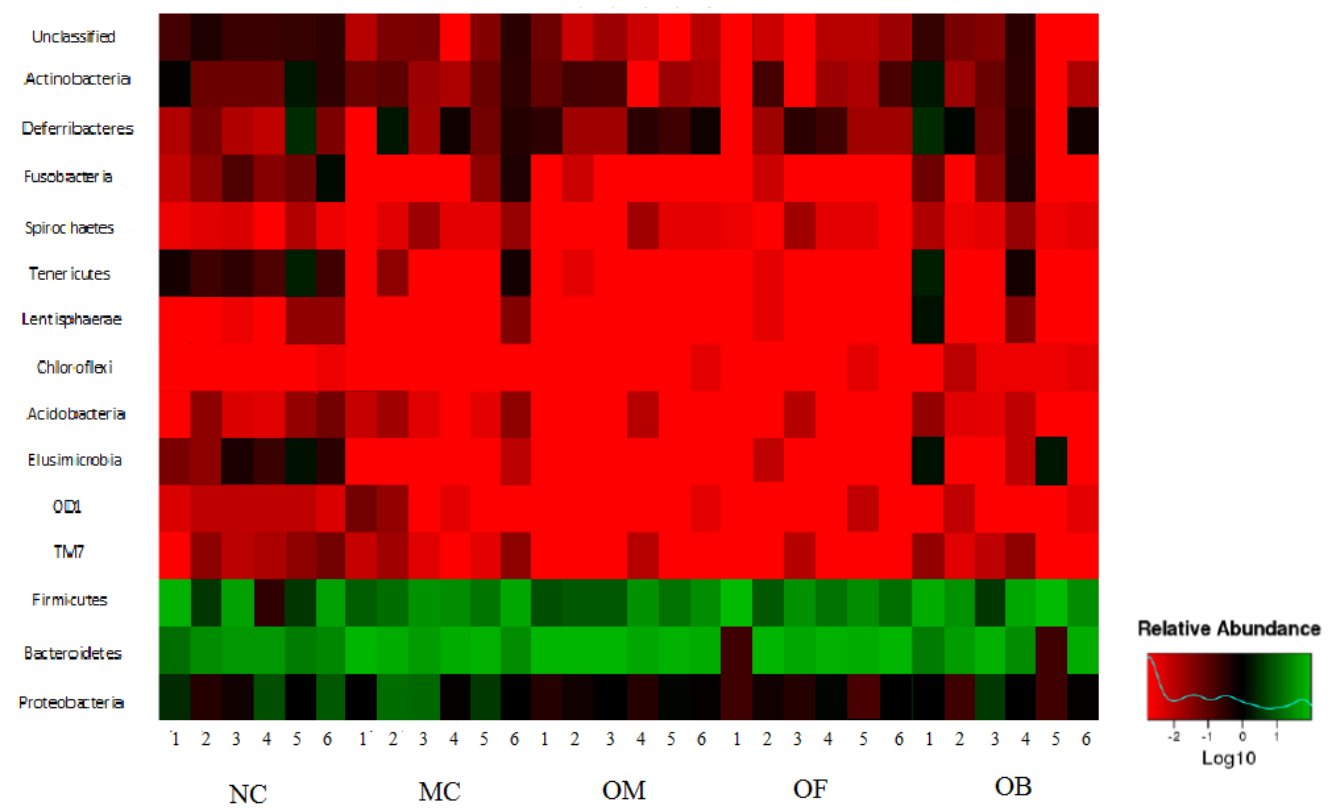

(B)

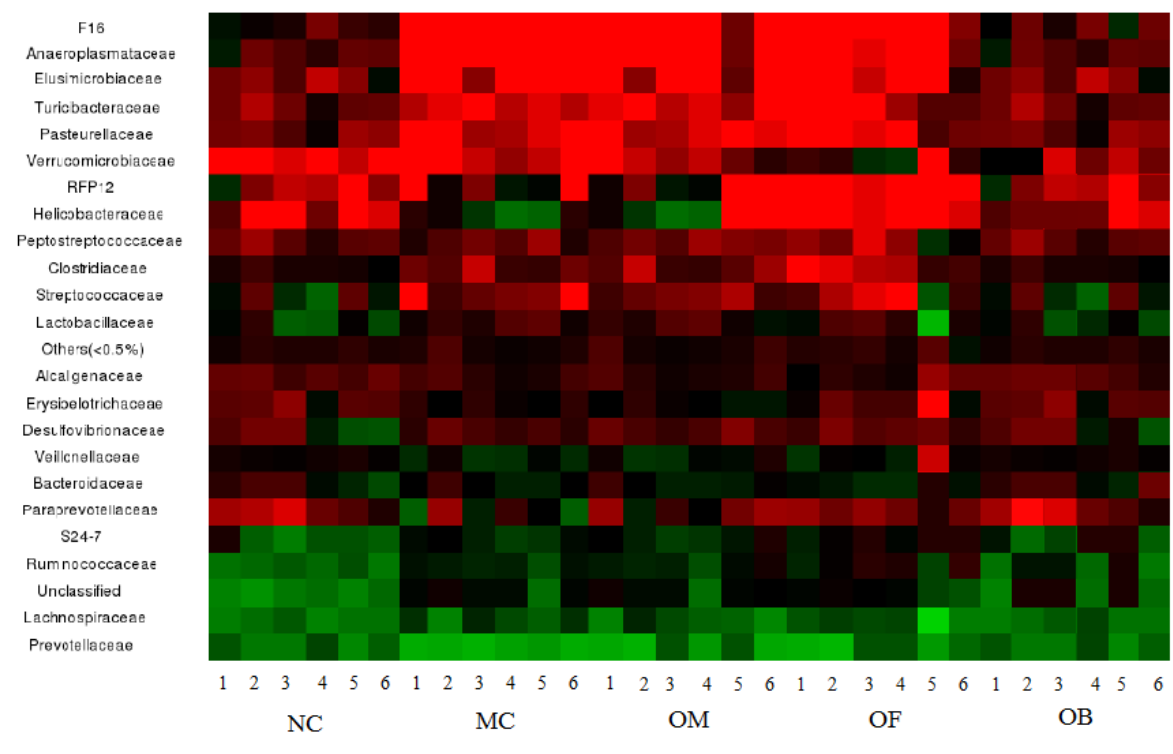

(C) 


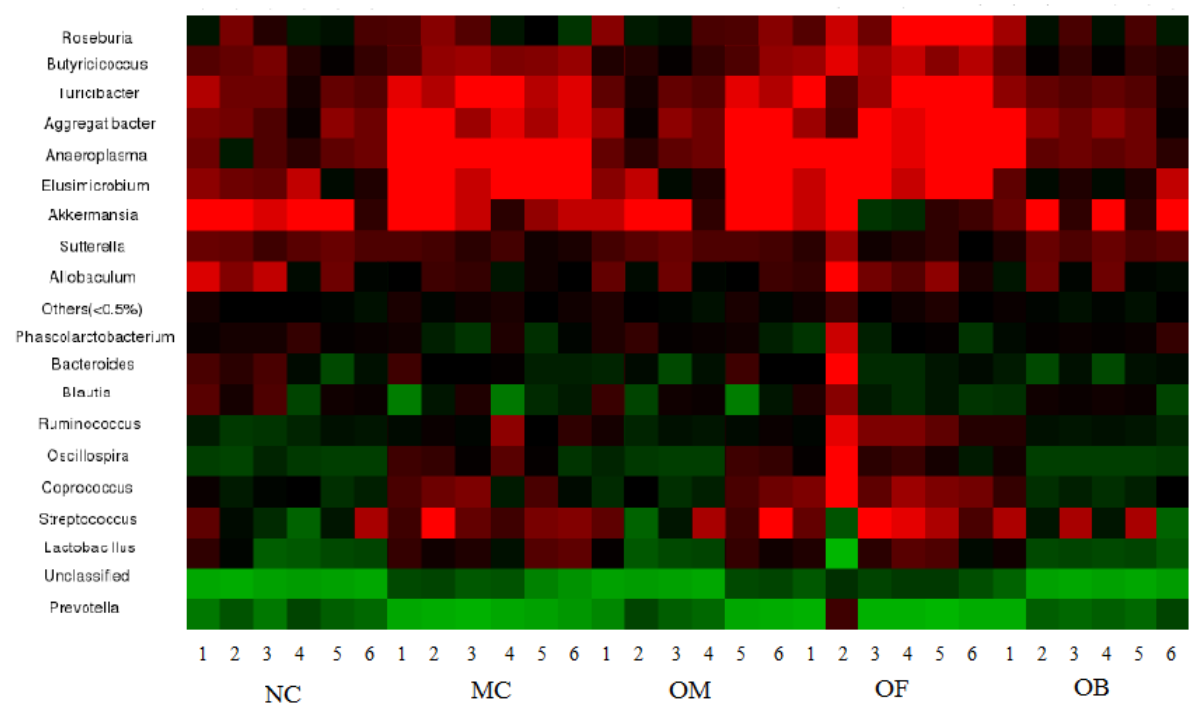

(D)

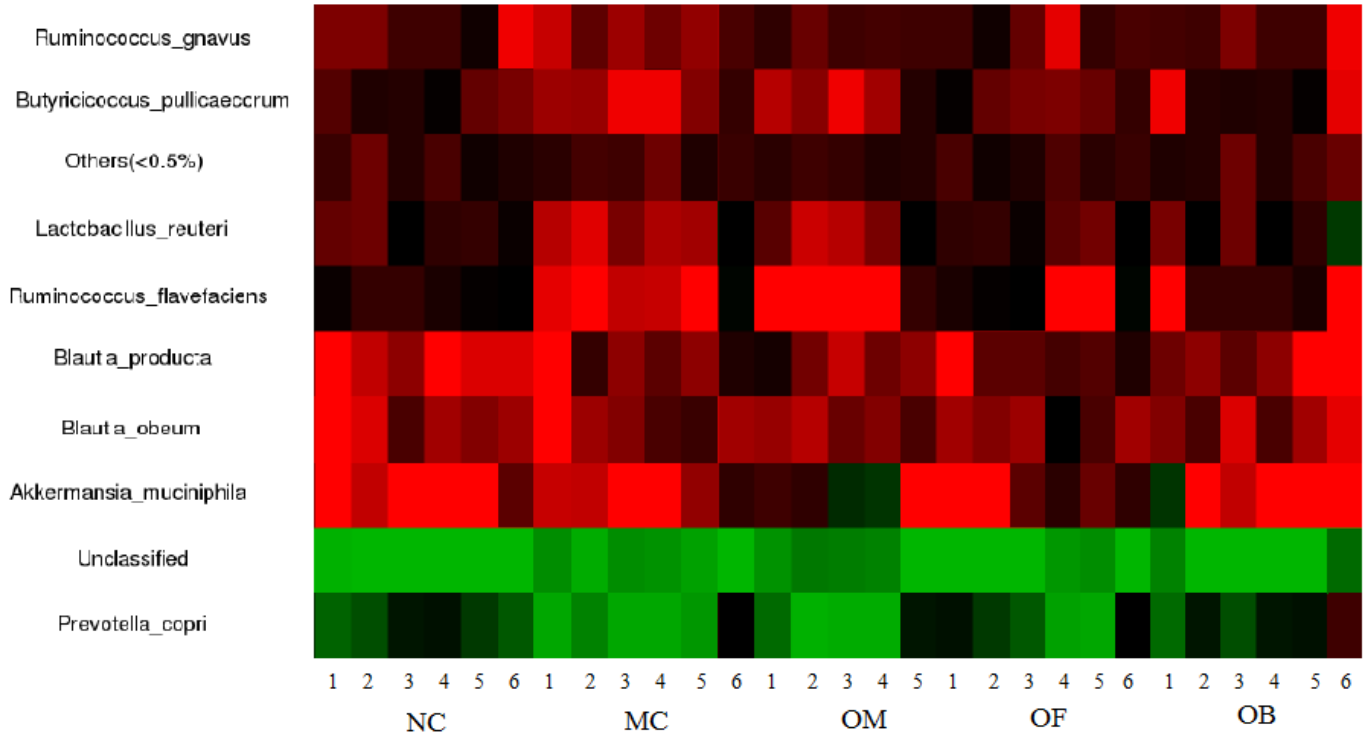


Figure 5. Overall structure of gut microbiota of rats in each group at $8 \mathrm{w}$.

(A)

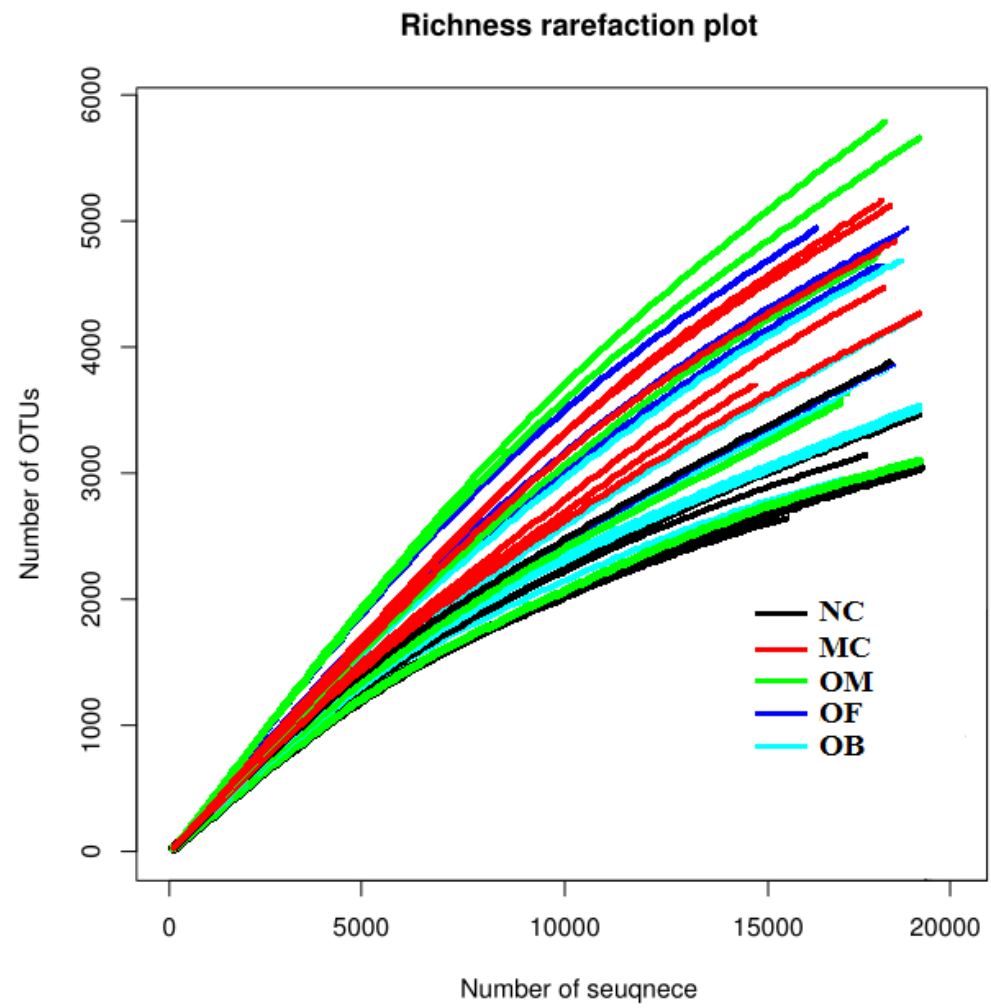

(B) 


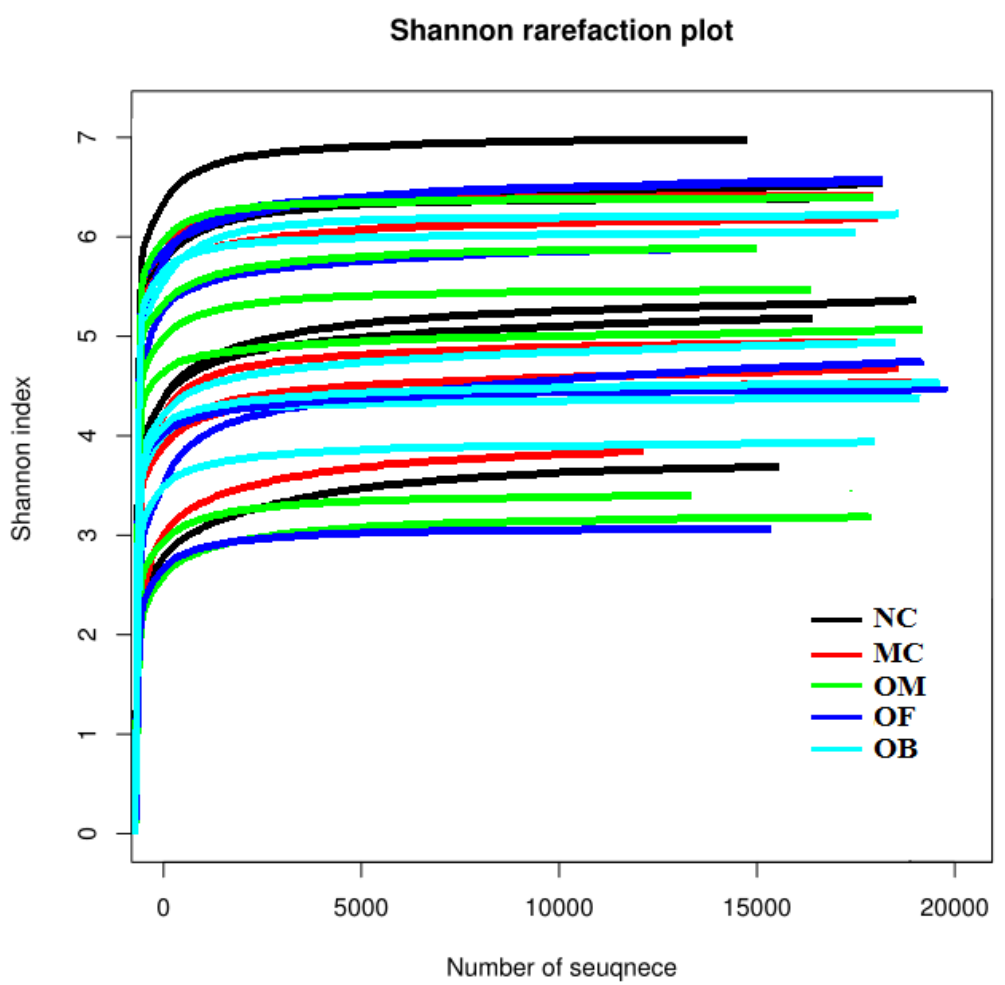

(C)

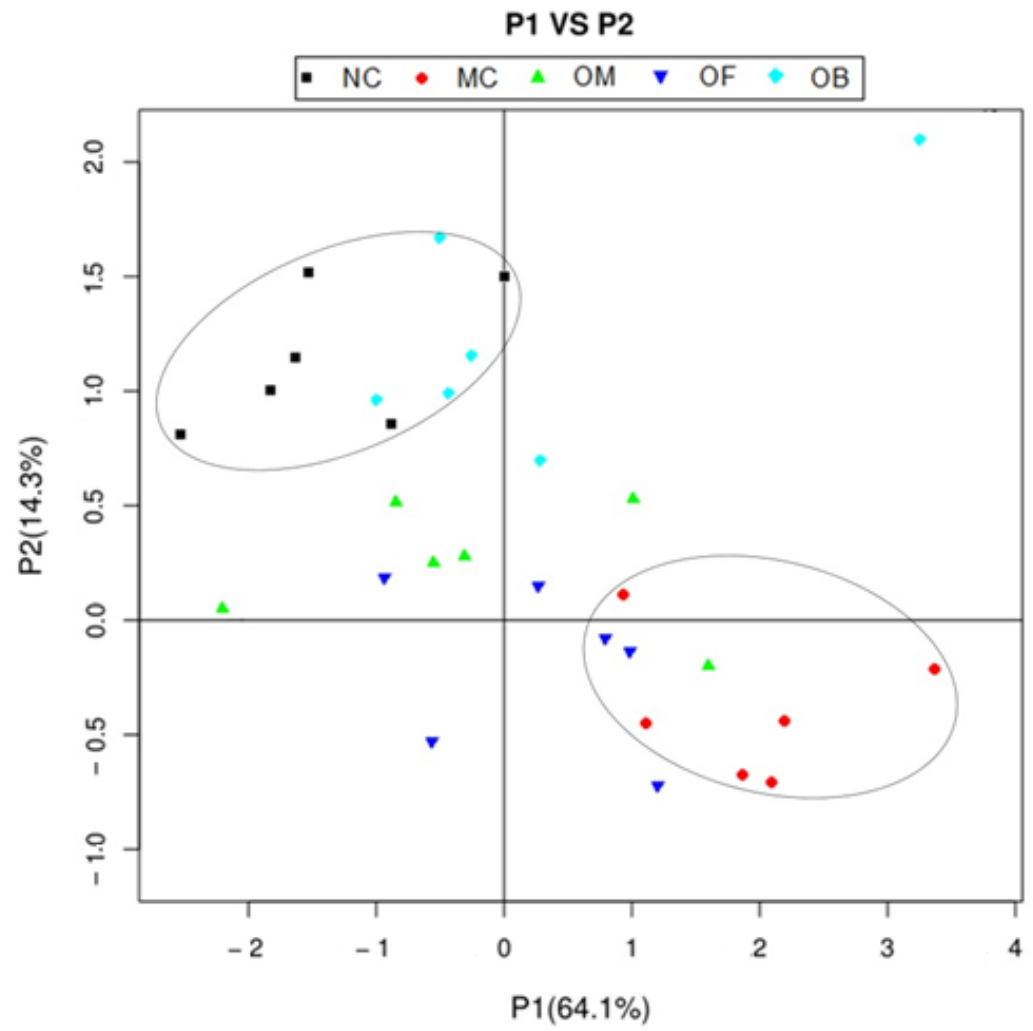

